\title{
Social Theory and the Politics of Big Data and Method
}

\section{Carlos Frade}

University of Salford (Manchester, UK)

\begin{abstract}
This article is an intervention in the debate on big data. It seeks to show, firstly, that behind the wager to make sociology more relevant to the digital there lies a coherent if essentially unstated vision and a whole stance which are more a symptom of the current world than a resolute endeavour to think that world through; hence the conclusion that the perspective prevailing in the debate lacks both the theoretical grip and the practical impulse to initiate a much needed renewal of social theory and sociology. Secondly, and more importantly, the article expounds an alternative view and shows by thus doing that other possibilities of engaging the digital can be pursued. The article is thus an invitation to widen the debate on big data and the digital and a call for a more combative social theory.
\end{abstract}

\section{Key words}

Actor-network theory; crisis; Machiavellian social theory; oligarchic metrics; oligarchic power; political economy; subjectivation; temporality; universal address

\section{Corresponding author:}

Carlos Frade, University of Salford, Frederick Rd Campus, Allerton, Salford M6 6PU, UK Email: c.frade@salford.ac.uk

\section{Introduction: crisis and renewal}

Social theory, and more specifically sociology, would seem to be at the crossroads of yet another crisis. Indeed so many crises permeate the history of the discipline that one could argue that crisis as a mode of temporal experience constitutes sociology's very mode of historical existence. Sociology's historicity would thus be that of an endemic crisis which unfolds in the form of both foundational crises and crises of exhaustion. On the one hand, the magnificent foundational crises of its beginnings, of its (re)commencement and principle, when astonishment and disquiet at the sight of the dismal wonders of the modern world, above all that most fateful power of our modern life, in Weber's famous expression, provided the impulse and the strength to create a new discipline. On the other hand, the dismal crises of 
exhaustion when, somewhat peremptorily and in a dramatic tone not exempt of a revealing contentment, sociology is pronounced in a nearly terminal state and its time declared to be up.

We only need to recall the recent proliferation of crisis pronouncements, in the nineteen sixties and seventies, for example, which includes Gouldner's (1971), but also others (see Bottomore 1975: chapter 3); or those that followed in the early eighties (Abrams, 1981; see Calhoun, 1987) and afterwards with the postmodern turn (Seidman, 1994; McLennan, 1995). But even if no crisis is explicitly declared and the feelings about the state and prospects of the discipline are more conflicting and mixed (Calhoun, 1995; Holmwood, 1996), yet, the crisis or its declaration always returns. For sociology, perhaps more than other social sciences, stands in so close a relation to the present that it is at least as much about analysing the present as it is about studying society. While this often leads sociology to simply reflect and register the ups and downs of its object, it has also served as the basis for begetting a strong desire, akin to the aforementioned foundational impulse although rarely having its strength, to revitalise a discipline the ambition of which does not always bear comparison with its actual capacity to meaningfully provide some orientation for action and the conduct of life.

The current crisis presents in principle all the ingredients which make the idea of crisis productive, that is - in my own interpretation of Koselleck's theses on the conceptual history of the notion of crisis (Koselleck, 2002: specially chapter 14) - a heightened sense of temporality defined by a felt disjunction between recurrence of the past and projection into the future which brings to the fore a tension-ridden relationship between time and agency. Announced as impending, and thus echoing Gouldner's forecasting mode, by Mike Savage and Roger Burrows in 2007, the current crisis' distinctiveness lies in three interrelated features: its object, empirical sociology - a designation whose demarcation is fairly clear but whose significance is rather ambiguous, as we shall see, in relation to the status of theory and other sociological "genres" like critique; its nature as a survival crisis affecting academic sociology; and the fact that while the urgent response the crisis demands is known and clear, which considerably lessens the productive tensions inherent in the experience of the crisis, what is uncertain is the willingness of academic sociologists to provide such response.

Let us summarise the reasons behind the impending crisis and the response proposed to avoid its consummation: it all comes down to the exponential growth of the automated production, use and analysis of transactional and other digital data by private corporations and governments. Such data ('Big Data' has become the tag name; from now on BD) are considered ever more relevant in social life - indeed the latter is increasingly seen as an 
enactment of the former. This poses a radical threat not only to the status of academic sociology, whose claim to 'jurisdiction' (Savage and Burrows, 2007: passim) over the study and analysis of social life is today more of a fantasy than a reality, but to its very existence. This is due to the fact that, crucially, 'the research of academic sociologists appears somewhat peripheral to the multifarious research circuits which are implicated in the constitution of a knowing capitalism' (Savage and Burrows, 2007: 888, original emphasis), while they themselves appear as secondary actors, as 'only one - and by no means the most privileged group vested in social research and analysis' (Savage, 2009: 157). This relentless march into disappearance or - what is almost the same but may be harder to bear - insignificance will not be halted unless academic sociologists recognise their true position and decide 'to get their hands "dirty" by' engaging with 'these kinds of "contaminated" data sources' (Savage and Burrows, 2009: 766; the 'need to get our hands dirty' is also emphasised in Ruppert, Law and Savage, 2013: 32, and in Adkins and Lury, 2012: 14; see also Uprichard, 2012b) or by 'casting our net wide, critically engaging with the extensive data sources which now exist, and not least, campaigning for access to such data where they are currently private' (Savage and Burrows, 2007: 896) - this is the proposed response, one that found a very favourable reception and has been or is in the process of being basically taken on.

'[W]e certainly seemed to have touched a nerve' - Savage and Burrows declare two years after the original paper (2009: 765). And no wonder that their appeal, which they qualify as 'provocative' (2009: 764 and 769) and, as Savage further discloses, even 'Machiavellian' (2009: 171; more on this clichéd signifier in the last section), struck a hypersensitive nerve, indeed an enduring and deeply resounding chord. The fact that their article has become the most cited one in Sociology in the last decade (Burrows and Savage, 2014: 1) we can understand if we take into account the shock wave it triggered in terms of debate and research agendas. For not only did it receive numerous positive and critical but sympathetic responses in the literature; it became a point of reference for reflection and debate, as it provided a clear focus around which emerging research strategies could converge, while it surely helped to transform existing research worries into more articulated concerns. To this it has to be added the magnetic pull of the BD issue, which allows it to meaningfully enlist in its entourage other important problems like the so-called Open Access to research publications or the right-wing politics of imposing the "impact" agenda on research. All this found public expression in terms of publications; thus, in addition to a number of individual articles and a special e-issue of Sociology (McKie and Ryan, 2012) centred on Savage and Burrows' article, there have appeared five special issues in specialised journals either focused entirely on this debate 
(Back and Puwar, 2012; Savage, 2013) or addressing central aspects of it such as 'measurement' (Adkins and Lury, 2012) and 'the empirical' (Adkins and Lury, 2009), or considering it in a broader historical perspective (Osborne, Rose and Savage, 2008). The newborn journal Big Data \& Society, edited by Evelyn Ruppert, a prominent participant in the debate, is unquestionably a major result thereof. Finally, the BD issue and the emergent field of digital sociology have lately become a growing object of publications and readings (e.g. Orton-Johnson and Prior, 2013).

It is essentially this literature that I address here. But this article is not a literature review, and the references just provided do not pretend to be exhaustive; nor do I consider that literature as a homogenous body. Rather, the article is an intervention in this debate. I seek to re-situate the $\mathrm{BD}$ issue in a different perspective and to disrupt the debate around it. The paper's two major aims are, firstly, to show that behind the wager to make sociology more central to capitalism's research circuits as response to the impending crisis there lies a coherent, but essentially unstated, set of ontological and epistemological assumptions and a whole practical attitude regarding social life, the digital world and action in the world. The purpose here is to bring out those assumptions and to show that the vision and stance they underpin are more a symptom of the current world than a resolute endeavour to think that world through. The latter is a fundamental prerequisite for the renewal of social theory and sociology; I contend that the perspective prevailing in the current debate on BD so far lacks both the theoretical grip and the practical impulse which will enable it to initiate such a renewal.

The second, even more important aim is to expound an alternative view and to show by thus doing that other possibilities do exist and can be pursued. In view of the conception of the digital deployed in the debate as something irresistible and the intimidating function such conception fulfils, the article is also a call against resignation and for a more combative social theory, one which is still able to feel disquiet, but never abandons hope. Only such capacity for disquiet, for wonder and astonishment can provide the impulse for a renewal of social theory - the impulse which was at the origin of the discipline and has to be at the core of its renewal(s). The paper is thus an invitation to widen the debate on BD and the digital, and to seriously consider so far unexamined perspectives and possibilities.

\section{An ontology of inexorable change, mobility and fluidity which breeds resignation}

It all starts with an object of attention described as the digital world or the world of online, live data generation devices. That world is conceived of along the well-known and in part 
stereotypical lines of fluidity, mobility and continuous acceleration. It is an ontological conception which, although it does capture some aspects of the digital world, is profoundly metaphysical and deeply flawed, for it privileges change (or, rather, a certain kind of change) while it is practically oblivious to the structural aspects which don't change but are inseparable from, and perhaps more significant than, what changes.

The problem is compounded by the fact that such ontology is rarely made fully explicit in the BD debate; rather it is tacit and unstated for the most part, which makes its presence even more compelling and its effects somehow subtler and more difficult to disentangle. Some participants in the debate tend to be noncommittal about that ontology and attribute it to others such as Law and Urry's well-known article (2004), a kind of precursor of the debate in what concerns its methodological stakes, or Latour. For example, Savage and Burrows (2007: 894) refer to 'the kinds of myriad mobilities, switches, transactions, and fluidities that are claimed to make up contemporary social life (Urry, 2003)'; in a similar way, Savage (2009: 162) refers to 'Latour's evocation of flow, mobility and contingency'. Others purport to take a more direct stand; this is the case of Les Back, when, relying on Law and Urry (2004), he refers to what current method cannot admit, namely: 'the fleeting, distributed, multiple, sensory, emotional and kinaesthetic aspects of sociality' (Back, 2012: 28). There are also instances of a more explicit and prolific use of the language of mobilities and flows (e.g. Büscher and Urry, 2009).

But whether explicit or tacit the ontology of fluidity, mobility and change lurks like a spectral but powerful presence around the debate. It is apparent both in the language resorted to, permeated as it is with terms such as mobility, transactions, and the like, including challenges and opportunities, and in the very construction of the overall arguments about the crisis and how to respond to it. Both, language and arguments, convey the idea that the object of attention (BD and data-generating devices) is something that exists in a very strong sense of existence, that is, not merely in abundance, but in the mode of an existence that grows, becomes more and more prolific and installs itself as routine processes, as e.g. in the following typical rendering, one among many, of this idea: "the proliferation of "social" transactional data which are now routinely collected, processed and analysed' (Savage and Burrows, 2007: 885). Three further features characterise that existence. Firstly, its movement is unidirectional: toward further and speedier growth and proliferation. Secondly, it finds practically no obstacles, no disruptions worth examining. Thirdly, and crucially, it 'materialize[s] new forms of sociality' or is 'materially implicated in the production, 
performance and knowledge of contemporary sociality' (Ruppert, Law and Savage, 2013: 24 and 34).

A dynamic existence that ceaselessly propagates and multiplies itself in this way is something daunting, all the more so when it is taken as a given and no sustained examination of what brings it into being is done - indeed such examination, involving one way or another as it does causation, is de facto rejected, as is well-known, in favour of 'sociological description' (Beer and Burrows, 2007: 11) and 'descriptive assemblage' (Savage, 2009), very much in line with Actor-Network Theory (Latour, 2005). Such existence thus appears as something inevitable and irresistible. It is, in brief, an intimidating existence to which one ought to submit. Subjective submission is not only presupposed in this conception of the digital but also tacitly implied as an imperative in the whole framing of the relation between social theory and BD. In my view this is probably the most effective "lesson" of the BD debate; being both presupposition and conclusion, it functions as a guarantee of submission to what exists. BD (or more generally, the digital) fulfils the same intimidating function as "the economy", "the markets", "investors" and similar ultimate authorities of intimidation, but it does so in a subordinate manner. For after all the digital is not a self-generating phenomenon; rather it is dependent on "knowing capitalism" ... which wants to "know everything" - the capitalism that matters to sociology according to Savage and Burrows (2009: 766).

We thus have a dynamic entity which is continuously moving fast and in a single direction: towards more and faster growth and expansion, and always toward the future, but a future with no promise other than the accelerated continuation of the present. A time is thus defined, the time of the digital, of networked communications, of BD: a time which ascends as it advances, which progresses not only in sheer volume but in technical efficiency. This is a linear and largely progressive time - a rather surprising idea. Was not this conception of time meant to be passé a long time ago, and more recently subjected to an influential methodological critique by Andrew Abbott (2001)? But this linear time encompasses a seemingly different temporality: the ephemeral and frenzied present involved in the recursive mediations of the online, digital world - a temporality which may well be called a presentless present, for it dissolves the tension between the past and the future which subjectively constitutes a true present in favour of a mere succession of instants and constantly shifting foci of attention. It is, in brief, a time without grip, without memory and without reach.

Emma Uprichard (2012a) has opportunely cautioned social researchers against the serious risk that the new genre of BD research runs of being stuck and trapped in the ahistorical time 
of the "now-casting", so that it may end up simply reflecting and reproducing the digital world instead of thinking it through. The latter risks being 'over-taken, even taken over' by the former, with the added consequence that such a 'temporal take-over of theory displaces sustained critical thought' (Dean, 2010: 1 and 2). The distance needed for thought, i.e. for the inseparable process of theory (conceptual development) and practice (conduct of free enquiry), can only be gained within a radically different temporality which I would like to call the temporality of subjectivation. I am aware that the BD debate, and Savage and Burrows' interventions in particular, are pervaded by a tacit but manifest distrust of any strong commitment or attachment. And yet, leaving aside other fundamental considerations, it is undeniable that only a steadfast commitment to the theoretical cum practical task of social theory can provide us the capacity to subtract ourselves not only from the fleeting urgencies and jouissances of the now-casting, but also from the seductions of, not to say the fixation on, the instant impact and the linear time that frames and justifies such stances.

This argument will certainly trigger immediate protestations and denials; and truly the recurrent and emphatic declarations of non-linearity, contingency and similar terms pointing to a like effect would seem to indicate that the argument is simply wrong. Thus, Adkins and Lury, to provide an example among many, argue that sociology has 'to confront a newly coordinated reality, one that is open, processual, non-linear and constantly on the move' (2009: 18). On closer examination, however, one can easily see that only in the context of a conception of linear time like the one just brought to light is it possible to make sense and understand the meaning of, first of all, the language of "challenges" and "opportunities" (with the respective "threats") to which a majority of participants in the debate profusely resort (e.g. Savage and Burrows, 2007 and 2009; Back and Puwar, 2012; Back 2012; Adkins and Lury, 2012; Savage, 2013; Ruppert, Law and Savage, 2013); and, secondly, of the overall argument within which such language is used, that is, the argument opposing a very dynamic and fast moving world (the digital) to a discipline characterised, as we shall see in more detail later on, as petrified, dogmatic and complacently sticking to habits and methods which are quickly losing relevance and efficacy - a discipline that runs the risk of being left behind, unless immediate and effective action is taken. In Les Back and Nirmal Puwar's words: 'The massive accumulation of digital data in the hands of corporations to generate (largely market driven) predictions is not approached as a threat which displaces the methodological edge of the sociologist, who faces an "empirical crisis" (Savage and Burrows, 2007) and is left behind in the wake of digitally accelerated forms of observation and construction' (Back and Puwar, 2012: 9, emphasis added). Even for the editors of one of the special issues devoted to the 
debate and major contributors to it, whose disagreement with the initial framing of the debate is more apparent than real, is there a clear sense of an inexorable time that moves ahead faster and faster and somehow interpellates us to urgently change gear and move with it: in fact, such a time brings opportunities which, unless 'embrace[d]' (Back and Puwar, 2012: 6; Back, 2012: 20), will for ever be lost.

In truth what prevails in the debate, rather than a sustained attempt to confront the digital, to intellectually penetrate BD and examine their constitution and the ways they model the social, is the desire to participate in it, to be a knowledge actor as befits 'knowing capitalism' hence the advocacy of 'campaigning for access to such data' as a right (Savage and Burrows 2007: 896); hence the fact that two of the most crucial issues as are the political economy of $\mathrm{BD}$ and the nature of the power constituting and driving the digital are not addressed at all.

\section{The political economy and the oligarchic power constitutive of the digital and big data: some preliminary remarks}

One of the merits of Savage and Burrows is to recognise the political character of BD. Unfortunately, they don't go far enough in this direction, for all the politics referred to in their and other participants' interventions - that is, mainly the politics of method, the politics of social data, the politics of measurement, transactional politics (Ruppert and Savage, 2012) are domain-specific politics which take the established order as a given. The politics of method, for example, is a proposed way for sociologists to address the methodological situation of the discipline entirely within the bounds of the established order, that is, to participate in 'knowing capitalism' - a desire which naturally dissuades its carriers from undertaking a sustained examination of those aspects of their object of desire which may expose and somehow undermine it as is the case of the form of power constitutive of the digital and its political economy. About the former there are no traces in the debate, while only Anna Gross refers to the latter and makes two relevant considerations: first, that the problem is not only a question of the politics of method, but also of the political economy of $\mathrm{BD}$; and secondly, that at stake in the latter is the question of ownership and the devices that serve to 'facilitate and secure specific forms of value' (Gross 2012: 126).

Given the scope of the question of the political economy of BD I can only point out here some very basic, indeed preliminary, aspects of it, starting from two very simple observations: first of all, BD is of course not raw material, let alone "raw data", but a corporate field, and, as such, entirely organised for the extraction and accumulation of value. Indeed BD is the 
ultimate corporate field, as it relies on a continuous production and capture of an apparently inexhaustible source of value: nothing less than "sociality", as the BD debate regularly refers to it, or, in a different social theory literature (e.g. Hardt and Negri, 2004), "the common". The second observation concerns the ways in which subjective acquiescence is obtained in that field and, more specifically, its regime of jouissance (enjoyment). This is crucial, for the imperative to enjoy, whose supreme emblems in our present include being connected and the social media, takes the form of specific and constant injunctions for the production of sociality (participate, like, share, choose and so forth), sociality which is then immediately and systematically captured, tracked and subjected to automated algorithmic devices and calculations which feed the results thus obtained back into the system, so that new searches, choices, etc. are shaped by those calculations, and so on in endlessly recurring loops.

All the searching, liking, etc. is divested of any symbolic value: every view and every expression of affect are made equivalent, injected into the data mass and subjected to the endless circulation of information. In this process the participants are construed and enacted as global 'prosumers' (Ritzer and Jurgenson, 2010), simultaneously producers and consumers, and every single move they make in the digital is automatically captured at the very time of its coming into existence and becomes an act of global 'prosumption'.

Divested of symbolic efficacy and made equivalent, every operation carried out in the digital acquires economic, exchange value. Value in this world, as defined by the algorithms designed to create, capture and measure it, is essentially the density and weight of the digital links, that is, of the social relations, and its graphic visualization brings into view the motley hierarchies of influence and the superb pyramidal figures they form - figures that provide a pretty close visualization of the form of power constitutive of the digital and BD but neglected in the literature: oligarchic power, ironically one of the oldest forms of power in human history, but today working on the basis of the latest technology of power: digitalised algorithms.

It is thus absolutely imperative, in my view, for social theory to recover this fundamental but forgotten category of political sociology: oligarchy. For the logic driving the digital and BD is not just a question of what has been Foucauldianly and very aptly termed 'algorithmic governmentality' (Rouvroy and Berns, 2013), fundamental as this is, but of oligarchic power in the first place, since it concerns submission or acquiescence, and this is a political rather than a technological or governmental thing. Now to understand what oligarchic power is and how oligarchic domination is exercised, it is not useful to remain at the empirical level and 
thus argue that an oligarchy is not a homogenous group, but internally divided, in conflict and so on. For oligarchies are not fixed groups; rather they grow ever-slimmer (in number), and it is this dynamics, today global in nature, what really matters. To these empirical observations we have thus to add a small but crucial detail concerning the oligarchic disposition and logic in order to understand better this category and the good work it can do today, as it did in the past (Machiavelli), and this is that an oligarchy is constituted by the parasitical relation it has with its Other, with the people, which the oligarchy relentlessly tries to keep as a dispersed and disorganised plebs so as to continue to dominate and exploit it.

Oligarchic power functions at various intertwined levels in the digital, e.g. in terms of oligopolistic corporate acquisitions such as Google's incorporation of ChoicePoint, a dataaggregating company, and DoubleClick, a behavioural targeting company (see Raley, 2013). Another fundamental aspect is the default mode of online interaction, particularly concerning remembering and consenting, which means that forgetting and rejecting are either the exceptions or impossible. The kernel of the whole process lies in the transformation of equivalence into inequality, but its very condition is constituted by the removal of the symbolic value of interactions, which is what allows the logic of dispersal and hierarchical rearrangement to take effect. This logic works by, firstly, capturing and correlating dispersed and disparate elements, which is what data are: creations of discreet, separate and separable units (e.g. clicks, search elements). But this is not all, for 'the imagination of data is in some measure always an act of classification, of lumping and splitting, nesting and ranking' (Gitelman and Jackson, 2013: 8). A second general step is then required; this consists in rearranging those elements (e.g. through algorithmic profiling, indexation) into distributions, mainly of a hierarchical kind, which rank participants, e.g. in terms of health and security risks, purchasing power, credit standing, etc. although all rankings are ultimately subsumable into the two truly fundamental ones: market and security. The process is traversed and shaped by advertising, which, consonant with the deep neoliberalism prevailing in the online, has become heavily behavioural and has given rise to extremely aggressive behavioural targeting companies. In this situation 'we have become the resource for data collection that vampirically feeds off of our identities, our "likes," and our everyday habits' (Gitelman and Jackson, 2013: 10). All there is here is prosumers and commodities; politically, the figure they make is that of a dispersed plebs summoned to the market.

Contrary to what we tend to think, the metrics that defines the digital algorithms is not different from the metrics that underpins indicators of "quality", "impact" measures and 
"feedback" forms. It is common to call it 'popularity metrics' (Marres, 2012: 157), but this is a misnomer which overlooks and obfuscates what is most important: first of all, the oligarchic logic that enacts and models the 'perverse authority dynamic', 'whereby things become more widely liked by virtue of being liked', which has 'become very much the currency of online media' (Marres, 2012: 155 and 156). Secondly, the "popular" at stake in such metrics - and this also valid for the recurrent claims that 'social media is now a fundamental part of popular culture' (Burrows and Savage, 2014: 2) - is essentially the oligarchic one, the dispersed plebs summoned to the market and enmeshed in the regime of jouissance.

\section{The case for a methodologically inventive academic sociology}

The digital world finds its obverse in the world of sociology, which is portrayed as static and self-indulgently refusing to follow suit. According to Savage and Burrows, academic empirical sociology is losing importance vis-à-vis “"commercial sociology" (2007: 887), and this process is only bound to quickly deepen due to the enormous research capacity existing outside academia. This is probably beyond doubt. Our question here lies in how the participants in the BD debate envisage the response, or lack thereof, of academic sociology to this situation.

Academic sociology, Savage and Burrows (2007) claim, tends to be self-indulgent and condescending towards others, i.e. potential rivals like commercial research. These seem to be deep-seated attitudes, so much so that, confronted with the critical situation affecting the discipline, academic sociologists are likely to, letting the old dispositional pattern set in, 'emphasize [their] superior reflexivity, theoretical sophistication, or critical edge' (p. 887); or 'be precious and condescending to those who work in the [non-academic] sector, and bemoan their limited awareness, their instrumentalism, and so forth' (p. 888). These and similar reactions involve 'taking refuge in the reassurance of our own internal world' (p. 887), complacency, when 'any complacency here is very misplaced' (p. 893), or a 'retreat into the comfort zone of generalized descriptions of the nature of our present' (Osborne, Rose and Savage, 2008: 520). These views seem to be widely shared; the diagnosis would be that, to the extent that sociology continues to be yoked to the old ways its survival as an academic discipline is more than doubtful. Some participants in the debate venture as far as to proclaim such sociology 'a dead sociology that is characterized as objectifying, comfortable, disengaged and parochial' (Back, 2012: 18). 
So, what to do in view of this situation? The answer lies - we already know - in 'getting our hands dirty' with BD. But, to do what? Well, to embrace methodological innovation and inventiveness or the practice of the 'politics of method' (Savage and Burrows, 2007: 895) and 'descriptive assemblage' (Savage 2009), that is, to 'abandon a sole focus on causality (which we are very bad at) and analysis and embrace instead an interest in description and classification' (Savage and Burrows, 2007: 896). In the current situation of academic sociology, any instantiation of such a politics is also presented as 'a further attempt (Savage and Burrows, 2007; Byrne, 2002) to jolt the discipline out of a methodological complacency that the "coming crisis" will exploit mercilessly to the detriment of us all' (Uprichard, Burrows and Byrne, 2008: 615).

It is here where the problems with the proposed survival strategy begin. For, what would be specific, distinctive, about an academic sociology practising such politics? Does this mean that commercial research is not engaged in methodological sophistication? According to Savage and Burrows nothing could be further from the truth. Commercial research, above all in the digital world, is much more sophisticated and data-rich and methodologically powerful than academic sociology, incomparably so - this is one of their central empirical arguments. I have striven to find the distinctiveness that academic sociology will bring but to no avail. In the final analysis this is seemingly not a problem for Savage and Burrow. It is not a problem because an academic sociology practicing such politics of method will be engaged in doing something which is 'an intrinsic feature of contemporary capitalist organization' (Savage and Burrows 2007: 895). This will guarantee, if not a place at the core of mighty capitalism, at least some share in it, because such methodologically sophisticated academic sociology can attract the interest of certain 'powerful agents', 'key agents' placed in strategic locations both at the level of the state and 'in the research apparatus of contemporary capitalist organizations' (Savage and Burrows 2007: 886 and 890). The survival of the discipline is thus dependent on the ability of academic sociologists to persuade those influential interests groups that what academic empirical sociology does is interesting for them. This labour of persuasion will surely be helped by 'campaigning', now presumably at the state level, 'for access to such data where they are currently private' (Savage and Burrows 2007: 896).

However, there are still some questions in need of an answer. To begin with, what would those powerful agents gain by accepting academic sociology as a partner - of course a very minor player, but still a player - since they themselves can do or can pay for the kind of things sociology is to give them? Once again one cannot find an answer, presumably because, 
somehow, it goes without saying. A methodologically inventive academic sociology would seem to be in a position to provide powerful and influential social agents and groups some pedigree, or something similar - which undoubtedly is an interesting argument, since after all those powerful agents, both corporate and governmental, have worked really hard, and rather successfully, in the last decades to disparage and degrade the university and its academics and students in the name of the infinitely superior worth of the market. Surprising as this may seem, yet Mike Savage and Roger Burrows probably have a point; and it is their merit to have spotted it, even if they don't say it, and to act accordingly: academic research, and a methodologically active sociological research in particular, may well be in a position to provide the corporate world, and even the state, with research that has legitimacy. I am not going to deny that this is a very important contribution that can indeed persuade those powerful groups on whom the fate of academic sociology ultimately depends. However, the prospects that academia will, under such a strategy, preserve in the long run the little pedigree it still seems to have are practically nil, since those legitimated in this way are the very actors bent on destroying academic independence, which is what makes academic research legitimate.

And then there are other problems: what about the genre of critique, for example, which in different ways has surely been a defining mark of the discipline - a genre which Savage and Burrows themselves repeatedly claim, e.g. as many as five times in the short paragraph which concludes their initial article, where they calmly state that by doing as they say 'we can renew the critical project of sociology' (2007: 896)? Critique here can only mean within clear limits, for one should not go as far as displeasing those powerful agents who are so important for the survival of the discipline. Such critique has nothing to do with 'the critical project of sociology' - indeed it is totally alien to that project. The same happens with theory, which is reclaimed after having practically been dismissed quite a few times as one of the typical delusions of the old sociology and as ineffectual in relation to the challenges posed by BD. In brief: critique, theory, public sociology (which is also claimed and praised), in truth anything can be considered part of the sociological politics of method - anything because none of these things really matter; they are simply adds-on which may help to develop glitzy narratives or sophisticated arguments, ornaments with which one embellishes the trade, but not the trade itself.

\section{Recapturing the present: the temporality of social theory}


In my view, a methodologically inventive social theory puts method in its place, which is (except for a very old-fashioned positivism) dependent on the "problematics" addressed and the theoretical framework that construes them. Now in what concerns problems and theory, it is evident that $\mathrm{BD}$ is a fundamental and decisive expression of contemporary capitalism. However, in the BD debate capitalism is essentially taken as a given, as if this were the consequence of taking too literally Latour's injunction 'don't focus on capitalism' (2005: 179). Contrary to the view that capitalism is too general, abstract and totalizing a term, the study of BD would gain much needed depth by relying on what Alberto Toscano (2012) has called 'seeing it whole', thus simultaneously pointing to perhaps the most salient flaw of actor-network theory - a flaw seemingly seen as a strength by the many participants in the debate who refuse depth and instead advocate description and assemblages. This emphasis on surface, the horizontal and the smooth fits and reflects pretty well contemporary capitalism's self-image, its semblance, which is certainly part of its real but cannot be mistaken for it.

Pursuing instead of repressing the desire to "see it whole" therefore involves bringing capitalism fully in the study of the digital and BD. But this would surely unsettle the position many participants in the debate have chosen, not to mention the fact that it would definitely displease those powerful agents referred to above, including research funding bodies. It is obvious that confronting BD in thought and therefore not recoiling from addressing capitalism and the oligarchic disposition that permeates society today involves some risks, indeed risk and courage. As I have argued elsewhere (Frade, 2009), this is a central point in Mills' The Sociological Imagination; however, it is never considered in a literature that not infrequently evokes Mills' work in its attempt to claim for itself that sociological quality of mind. When this is lacking, when one is oneself in a comfortable position involving no risk, one has neither the right nor the credentials to indict the discipline and admonish its practitioners for being complacent and taking refuge in comfort zones. After all, since both positions are equally comfortable, it is up to everyone to judge whether to swim with the stream has any more merit than to hang on the banks.

Social theory, and particularly sociology as an academic discipline, has a serious problem of address. Not because it lacks one, but because it has many, and is perhaps too concerned to please them. We have just seen that the newly proposed academic empirical sociology based on the politics of method has a privileged addressee: knowing capitalism's key agents and interests. We can also see how sociology - and this is very much the case of British sociology - strives to appeal and show its relevance to society at large and to as many publics as 
possible. It is on this impulse, I believe, on what in it is reminiscent of universality rather than of a tendency to pay homage to opinions and identities, that a renewed discipline can be built - an impulse one can glimpse today behind Discover Society, the renewed version of New Society devoted to present social research to a wider public. This means that it is the universal address that matters, so that audiences and any other particular groups, insofar as they are constituted by being holders of stakes or particular interests, disappear as such from the address of social theory and are addressed as thinking beings. This is so because social theory, sociology and the social sciences in general are addressed to all, and therefore to anyone, in their condition as thinking beings. The most decisive consequence of the universal address (all, without distinctions, and so, in the figure of the singular universal, anyone), assuming that it is taken on and therefore deployed on an everyday basis as part of a praxis, is that it enables social theorists and sociologists to regain and maintain that inner independence without which they risk falling prey to the tastes, opinions and interests of the groups they may seek to impress. This is the only power social theory and sociology have - it may not be a very impressive one, but it is the only real power they have.

It is in connection with the universal address, but specifically concerning the politics of method, that I would like to propose a moratorium on measurement and data gathering or, if this is considered too sacrilegious, then a total reorientation of those activities towards tracking and measuring the super-wealthy's and corporations' tax-dodge schemes, above all organisational arrangements which are quasi-pure modes of agency in that they dress themselves in a variety of mutable organisational forms with in-built mechanisms and immunities against legal and statistical inscription and traceability (see Frade, 2007, for more details), and the huge wealth defense industry working for them.

The universal address, the quest to see it whole and the reorientation of measurement and data gathering are central for social theory to recover the present and be able to image a future. They are also essential to undo the ruinous depoliticisation that pervades the BD debate and to a rather considerable extent social theory and sociology themselves. It may be worth mentioning, in connection with this grave problem of depoliticisation, Bruno Latour's puzzlement (2005: 252) about the fact that actor-network theory 'has been accused of two symmetric and contradictory sins', namely: of 'extend[ing] politics everywhere' and of 'indifference to inequalities ... being content only to connive with those in power' (2005: 251). Actually this is not a bad characterisation of depoliticisation; only Latour seems to believe that the latter does not involve a very specific politics. It is not only that 'they [the two 
sins] are not necessarily contradictory' (2005: 251), it is that they are the two necessary sides of a single politics, a depoliticising politics which feels at home within the established order. Of course the politics of actor-network theory are probably not of a piece. And yet the doubts about such politics, or at least Latour's, are considerably clarified, even at some point cleared up, by this declaration: 'ANT is nothing but an extended form of Machiavellianism' (Latour, 2005: 252). Indeed there is something in this declaration which definitely exceeds Latour's attempted enunciative modality, to wit: the recourse to the most vulgar form an antiMachiavelli propaganda, which places Latour squarely, whether out of ignorance or craft is of little consequence, on the other side of politics.

Now, as it happens, the social theory I have begun to outline in the above pages is a deliberate Machiavellian social theory, one totally opposite to the "Machiavellianism" advocated by Latour and some participants in the BD debate. Suffice it to say, to avoid widespread misunderstandings and deep-rooted prejudices, that Machiavelli's is a revolutionary thought of emancipation unambiguously addressed against all kinds of resignation, fatalism and cynicism, and involving a very specific revolutionary project of liberation against the oligarchy. This is the reason why the oligarchy undertook an unprecedented large-scale campaign against Machiavelli which goes under the name of "Machiavellianism" and continues to be highly effective today. Naturally in this undertaking the oligarchy was helped, in what is a rather strong historical link worth further investigation, by many intellectuals from both its own ranks and other social stations - most famous amongst them are those known as 'court humanists' (Frade, 2013). It seems to me that it is from these court humanists, rather than from Machiavelli, that the proponents of an extended Machiavellianism have gained their inspiration.

A Machiavellian social theory requires a permanent disposition to confront the world in thought, i.e. in theory and practice, and to do so from its own standpoint and by means of a disciplined conduct of enquiry of its own in terms of temporality and methods. Traversing the social sciences and being traversed by them, such social theory is not confined to studying what there is, but primarily seeks to understand the transformative potential existing in reality, to unearth the possibilities for emancipatory change and to examine in detail the ways and means whereby such possibilities are stifled.

A Machiavellian social theory trusts the people. This is a consequence, and not a mere strategic rule, of the universal address, of the idea that people, women and men, can think. It involves self-confidence and, as Machiavelli contended, hard but beautiful work. Today one 
wonders whether social theory and sociology have the self-confidence required to be Machiavellian.

\section{Acknowledgements}

An initial sketch of this paper was presented at the ESA (European Sociological Association) 2013 Conference held in Torino (Italy). It seemed to arouse quite some interest among the participants and I am grateful to them for the many comments and critiques it received.

\section{References}

Abbott A (2001) Time Matters: On Theory and Method. Chicago: University of Chicago Press.

Abrams P (1981) The Collapse of British Sociology? In: P Abrams, R Deem, J Finch and P Rock (eds), Practice and Progress: British Sociology 1950-1980. London: Allen and Unwin.

Adkins L and Lury C (2012) Introduction: special measures. The Sociological Review, 59(S2): 5-23.

Adkins L and Lury C (2009) Introduction: what is the empirical. European Journal of Social Theory, 12(1): 5-20.

Back L (2012) Live sociology: social research and its futures. The Sociological Review 60(S1): 18-39.

Back L and Puwar N (2012) A manifesto for live methods: provocations and capacities. The Sociological Review 60(S1): 6-17.

Beer D and Burrows R (2007) Sociology and, of and in Web 20: Some initial considerations. Sociological Research Online 12(5): 17.

Bottomore T (1975) Sociology as Social Criticism. London: Allen and Unwin

Burrows R and Savage M (2014) After the crisis? Big Data and the methodological challenges of empirical sociology. Big Data \& Society 1(6): 1-6.

Büscher M and Urry J (2009) Mobile methods and the empirical. European Journal of Social Theory 12(1): 99-116.

Calhoun C (1995) Critical Social Theory: Culture, History and the Challenge of Difference. Oxford: Blackwell.

Calhoun C (1987) History and sociology in Britain: a review article. Comparative Studies in Society and History, 29(3): 615-625.

Dean J (2010) Blog Theory: Feedback and Capture in the Circuits of Drive. Cambridge: Polity Press.

Frade, C (2013) An Altogether New Prince Five Centuries On: Bringing Machiavelli to Bear on Our Present. Situations, 5(1): 35-60.

Frade, C (2009) The sociological imagination and its promise fifty years later: Is there a future for the social sciences as a free form of enquiry? Cosmos and History, 5(2): 9-39. 
Frade, C (2007) Gobernar a otros y gobernarse a sí mismo según la razón política liberal. Revista Española de Investigaciones Sociológicas, 119(3): 35-63.

Hardt M and Negri A (2004) Multitude: War and Democracy in the Age of Empire. New York: Penguin.

Gitelman L and Jackson V (2013) Introduction. In: Gitelman L (ed.) “Raw Data” is an Oxymoron. Cambridge, MA: MIT, 1-14.

Gouldner A (1971) The Coming Crisis of Western Sociology. London: Heinemann.

Gross A (2012) The economy of social data: exploring research ethics as device. The Sociological Review, 59(S2): 113-129.

Holmwood JM (1996) Founding Sociology? Talcott Parsons and the Idea of General Theory. London: Longman.

Koselleck R (2002) The Practice of Conceptual History: Timing History, Spacing Concepts. Stanford, CA: Stanford University Press.

Latour B (2005) Reassembling the Social. Oxford: Clarendon Press.

Law J and Urry J (2004) Enacting the social. Economy and Society, 33(3): 390-410.

Marres N (2012): The redistribution of methods: on intervention in digital social research, broadly conceived. The Sociological Review, 60(S1): pp 139-165.

McLennan G (1995) After postmodernism: back to sociological theory? Sociology, 29(1): 117-32.

McKie L and Ryan L (eds) (2012) Introduction to e-special issue: Exploring trends and challenges in sociological research. Sociology 46(6): 1-7.

Orton-Johnson K and Prior N (eds) (2013) Digital Sociology: Critical Perspectives, Basingstoke: Palgrave Macmillan.

Osborne T, Rose N and Savage M (2008): Editors' Introduction Reinscribing British sociology: some critical reflections. The Sociological Review, 56(4): 519-534.

Raley R (2013) Dataveillance and Counterveillance. In: Gitelman L (ed.) "Raw Data” is an Oxymoron. Cambridge, MA: MIT, 121-145.

Ritzer G and Jurgenson N (2010) Production, consumption, prosumption: The nature of capitalism in the age of the digital 'prosumer'. Journal of Consumer Culture, 10: 13-36.

Rouvroy A and Berns T (2013) Gouvernementalité algorithmique et perspectives d'émancipation: Le disparate comme condition d'individuation par la relation? Réseaux, 31(177): 163-196.

Ruppert E, Law J and Savage M (2013) Reassembling social science methods: the challenge of digital devices. Theory, Culture \& Society, 30(4): 22-46.

Ruppert E and Savage M (2012) Transactional politics. The Sociological Review, 59(S2): 7392.

Savage M (2013) The 'Social Life of Methods': a critical introduction. Theory, Culture \& Society, 30(4): 3-21.

Savage M (2009) Contemporary sociology and the challenge of descriptive assemblage. European Journal of Social Theory, 12(1): 155-174.

Savage M and Burrows R (2007) The coming crisis of empirical sociology. Sociology, 41(5): 885-899. 
Savage M and Burrows R (2009) Some further reflections on the coming crisis of empirical sociology. Sociology, 43(4): 762-772.

Seidman S (1994) Contested Knowledge: Social Theory in the Postmodern Era. Oxford: Blackwell.

Toscano A (2012) Seeing it whole: staging totality in social theory and art. The Sociological Review 60(S1): 64-83.

Uprichard E (2012a) Being stuck in (live) time: the sticky sociological imagination. The Sociological Review, 60(S1): 124-138.

Uprichard E (2012b): Dirty data: longitudinal classification systems. The Sociological Review, 59(S2): 93-112.

Uprichard E, Burrows R and Byrne D (2008) SPSS as an 'inscription device': from causality to description? The Sociological Review, 56(4): 606-622.

Carlos Frade is Senior Lecturer in Sociology at the University of Salford (Manchester, UK). His research is concerned with the renewal of social theory along classical (Machiavellian, Marxian, Weberian) and contemporary (Badiouian) lines; it focuses on the relationship between subjectivity and power and on the possibilities for subjectivation today. He has recently published in journals such as Theory, Culture \& Society, Situations, Cosmos and History, and Revista Española de Investigaciones Sociológicas. He is currently preparing a book on social theory. 